\title{
Peptide Mix from Olivancillaria hiatula Interferes with Cell-to- Cell Communication in Pseudomonas aeruginosa
}

\author{
Edward Ntim Gasu, ${ }^{1,2}$ Hubert Senanu Ahor $\mathbb{D}^{1},{ }^{1}$ and Lawrence Sheringham Borquaye $\mathbb{C}^{1,2}$ \\ ${ }^{1}$ Central Laboratory, Kwame Nkrumah University of Science and Technology, Kumasi, Ghana \\ ${ }^{2}$ Department of Chemistry, Kwame Nkrumah University of Science and Technology, Kumasi, Ghana
}

Correspondence should be addressed to Lawrence Sheringham Borquaye; slborquaye@gmail.com

Received 10 July 2019; Accepted 3 September 2019; Published 24 September 2019

Academic Editor: Xiaoling Miao

Copyright ( 2019 Edward Ntim Gasu et al. This is an open access article distributed under the Creative Commons Attribution License, which permits unrestricted use, distribution, and reproduction in any medium, provided the original work is properly cited.

\begin{abstract}
Bacteria in biofilms are encased in an extracellular polymeric matrix that limits exposure of microbial cells to lethal doses of antimicrobial agents, leading to resistance. In Pseudomonas aeruginosa, biofilm formation is regulated by cell-to-cell communication, called quorum sensing. Quorum sensing facilitates a variety of bacterial physiological functions such as swarming motility and protease, pyoverdine, and pyocyanin productions. Peptide mix from the marine mollusc, Olivancillaria hiatula, has been studied for its antibiofilm activity against Pseudomonas aeruginosa. Microscopy and microtiter plate-based assays were used to evaluate biofilm inhibitory activities. Effect of the peptide mix on quorum sensing-mediated processes was also evaluated. Peptide mix proved to be a good antibiofilm agent, requiring less than $39 \mu \mathrm{g} / \mathrm{mL}$ to inhibit $50 \%$ biofilm formation. Micrographs obtained confirmed biofilm inhibition at $1 / 2$ MIC whereas $2.5 \mathrm{mg} / \mathrm{mL}$ was required to degrade preformed biofilm. There was a marked attenuation in quorum sensing-mediated phenotypes as well. At $1 / 2$ MIC of peptide, the expression of pyocyanin, pyoverdine, and protease was inhibited by $60 \%, 72 \%$, and $54 \%$, respectively. Additionally, swarming motility was repressed by peptide in a dose-dependent manner. These results suggest that the peptide mix from Olivancillaria hiatula probably inhibits biofilm formation by interfering with cell-to-cell communication in Pseudomonas aeruginosa.
\end{abstract}

\section{Introduction}

Drug resistance in human health and agriculture is a major hurdle in efforts towards the achievement of Goals 2 and 3 of the Sustainable Development Goals-achieving zero hunger and good health and well-being for all [1-3]. Due to indiscriminate use of antibiotics in aquaculture, poultry, and livestock farming, the incidence of antibiotic resistance is on the rise. The incidence of antibiotic resistance could increase the cost of meat and fish production as new drugs will be required to manage hitherto uncomplicated infections. Additionally, the yield of these food produces could potentially plummet and thus threaten global efforts in achieving food sufficiency [4]. Meanwhile, many antibiotics used to treat various lifethreatening and debilitating human infections have lost their efficacy, and a return to the pre-antibiotic era is on the horizon. Antibiotics are rapidly losing their efficacy primarily due to extensive, unrestricted, and often inappropriate use of most antibiotics [5]. The presence of sub-standard drugs on the markets of many developing countries also contributes to the loss of efficacy of antibiotics and hence antibiotic resistance [6]. Healthcare costs are on the rise due to antibiotic resistance, and the economic impact of morbidity and mortality due to failed treatments as a result of antibiotic resistance is enormous [7-10]. Pathogenic microbes utilize a variety of strategies to overcome the action of antimicrobial agents. These include the development or acquisition of resistance genes, formation of specialized persister cells, alteration of antimicrobial agent and/or antimicrobial target sites, the use of efflux strategies, and biofilm formation, amongst others [11-13]. Unfortunately, these pathogens seem to have outpaced our capacities to manage them. 
Biofilm formation, where microorganisms secrete a covering of extracellular polymeric substance (EPS) around them, is one of many strategies utilized by bacteria to diminish the effects of antibiotics and thus establish resistance. Bacteria within biofilms benefit from protection against host immune systems and are shielded from lethal antibiotic doses [14-16]. Pseudomonas aeruginosa ( $P$. aeruginosa) is a model biofilmforming bacteria and an opportunistic pathogen implicated in cystic fibrosis-related respiratory infections and chronic infections in immunocompromised patients [17]. Due to its ability to produce proteases, $P$. aeruginosa contributes largely to host tissue degradation as well as meat and protein-rich food spoilage [17-19]. The expression of genes associated with biofilm formation in $P$. aeruginosa is controlled by cell-to-cell communication, referred to as quorum sensing (QS), and multiple studies have shown that a strain of $P$. aeruginosa defective in QS is unable to form biofilm [20-23]. Additionally, QS has been shown to interfere with the expression of various $P$. aeruginosa virulence factors such as pyoverdine, pyocyanin, and proteases. QS also mediates surface motility, growth inhibition, and antibiotic production [24]. As such, the QS machinery in $P$. aeruginosa has been suggested as a plausible target for the development of therapeutic agents [25].

Strategies for biofilm treatment include prevention of microbial surface attachment, inhibition of biofilm development by killing early surface-colonizing bacteria with biofilm-forming potential, interference with quorum sensing, and eradication of mature biofilms [26]. Various natural products capable of attenuating biofilm formation and inhibiting QS have been reported in the literature [23, 27]. A class of compounds that have shown promise in interfering with QS-mediated processes such as biofilm formation are peptides [10, 28, 29]. Antimicrobial peptides (AMPs) function by targeting microbial cell membrane, binding with DNA to inhibit protein synthesis and detoxifying lipopolysaccharides. AMPs have been shown to be active even against multidrug-resistant microorganisms [30]. The exploration of AMPs could potentially expand the available options for eradicating bacterial biofilms.

Many marine invertebrates survive ocean surface biofouling and microbial attack by relying solely on their innate immune system which is principally composed of peptides. These peptides are secreted at very high concentrations in order to escape dilution by surrounding seawater and enhance efficacy. AMPs from these sources can be target specific, charged, and amphipathic [31] and could therefore be utilized as potential agents against biofilm-forming bacteria. This work sought to explore the biofilm inhibitory capabilities of the peptide mix extracted from the marine mollusc, Olivancillaria hiatula, and evaluate the potential of the peptide mix to interfere with some QS-controlled processes in $P$. aeruginosa.

We herein report that the peptide mix from Olivancillaria hiatula inhibits biofilm formation in P. aeruginosa and eradicates pre-formed biofilm as well. Additionally, the peptide mix inhibits the expression of some virulence factors such as pyoverdine, pyocyanin, and proteases at sub-lethal doses and has a significant impact on the swarming motility of $P$. aeruginosa. Together, these results suggest that the peptide mix attenuates biofilm formation by interfering with cell-to-cell communication in $P$. aeruginosa.

\section{Materials and Methods}

2.1. Chemicals. All chemicals were of analytical grade and were purchased from Sigma-Aldrich, St. Louis, MO, USA, unless stated otherwise. Gentamicin was prepared in sterile MilliQ water.

2.2. Sample Collection and Identification. Molluscs were collected from the shores of a beach at Eikwe $\left(4^{\circ} 58^{\prime} 00^{\prime \prime} \mathrm{N}\right.$ $2^{\circ} 28^{\prime} 47^{\prime \prime} \mathrm{W}$ ), in the Western Region of Ghana, and kept on ice. Samples were then transported to the Department of Chemistry, Kwame Nkrumah University of Science and Technology (KNUST), Kumasi, and stored in a refrigerator at $4^{\circ} \mathrm{C}$. Organism was identified at the Department of Fisheries and Marine Sciences, University of Ghana, Legon, as Olivancillaria hiatula.

2.3. Peptide Extraction. The peptide mix was obtained by the method described by Sathyan with some modification [32]. In iced state, shells were removed and the whole body tissue was pulverized. Tissue slurry was added to $10 \%(\mathrm{v} / \mathrm{v})$ acetic acid and kept for 12 hours at $4^{\circ} \mathrm{C}$. The mixture was centrifuged to remove debris, retaining supernatant (acetic acid digest). Ice-cold acetone $(25 \mathrm{~mL})$ was then added to the supernatant while shaking, and this was kept at $4^{\circ} \mathrm{C}$ for 24 hours to facilitate peptide precipitation. The precipitates were collected by centrifuging at $5000 \mathrm{rpm}$ for 15 minutes. Precipitates were then frozen at $-80^{\circ} \mathrm{C}$. Nitrogen gas was used to blow out traces of solvents after freezing at $-80^{\circ} \mathrm{C}$. The peptides were reconstituted in $25 \%$ acetonitrile (ACN) prepared in $0.1 \%$ trifluoroacetic acid (TFA) to give $5 \mathrm{mg} / \mathrm{mL}$ stock solution and stored at $4^{\circ} \mathrm{C}$ prior to use $[32,33]$.

2.4. Characterization of Peptide Mix by Infrared Spectroscopy. The infrared spectrum of the peptide mix was acquired using a Fourier transform infrared equipment (UATR Two, PerkinElmer, Waltham, MA, USA) by scanning the regions between $4000 \mathrm{~cm}^{-1}$ and $400 \mathrm{~cm}^{-1}$ followed by baseline correction.

2.5. Bacterial Strain and Growth Conditions. Pseudomonas aeruginosa ATCC 4853 was obtained from the Department of Pharmaceutics, Faculty of Pharmacy and Pharmaceutical Sciences of the College of Health Sciences, KNUST. Unless indicated otherwise, the bacteria were grown at $37^{\circ} \mathrm{C}$ on nutrient agar or in nutrient broth (Oxoid, United Kingdom). Bacteria colonies on nutrient agar were used to prepare colony suspensions in sterile saline, adjusted to 0.5 McFarland standard, and further diluted in sterile doublestrength nutrient broth to give $\sim 2 \times 10^{5} \mathrm{CFU} / \mathrm{mL}$.

2.6. Minimum Inhibitory Concentration. The minimum inhibitory concentration (MIC) of the peptide extract and 
gentamicin was determined by the broth dilution method described by Wiegand and coworkers with some modification [34]. Twofold serial dilutions of the peptide mix or standard gentamicin were prepared to obtain a concentration range of 2.5 to $4.88 \times 10^{-3} \mathrm{mg} / \mathrm{mL}$ in a 96 -well polypropylene microtiter plate (Thermo Scientific, UK). Overnight culture of $P$. aeruginosa was adjusted to 0.5 McFarland standard in sterile saline and subsequently inoculated in double-strength nutrient broth to an inoculum size of $\sim 2.0 \times 10^{5} \mathrm{CFU} / \mathrm{mL}$. Fifty microliters of inoculum was added to each well to a total volume of $100 \mu \mathrm{L}$ and incubated at $37^{\circ} \mathrm{C}$ for 24 hours. MTT (3-(4,5-dimethylthiazol-2-yl)-2,5diphenyltetrazolium bromide) was added to each well and incubated for 30 minutes. The MIC was determined as the lowest concentration of peptide extract that inhibited growth of test organism which was indicated by the absence of purple coloration after incubation. Sub-MICs were concentrations at which the growth of bacteria was not affected after 24 hours. All tests were performed in triplicate.

2.7. Bacterial Growth Curve. The growth of $P$. aeruginosa $\left(\sim 2 \times 10^{5} \mathrm{CFU} / \mathrm{mL}\right)$ in the presence of MIC and sub-MICs of peptides was evaluated by optical density (OD) measurements. Briefly, microplates were prepared with serial dilutions of the peptides and bacteria (as for the MIC assay) and incubated at $37^{\circ} \mathrm{C}$ with 3 seconds of shaking, followed by OD $(600 \mathrm{~nm})$ measurements every hour for 24 hours (BioTeK ${ }^{\circledR}$ Synergy H1 Multimode Microplate Reader, Germany). Growth curves of $\mathrm{OD}_{600}$ measurements against time were plotted.

2.8. Evaluation of Biofilm-Forming Ability of P. aeruginosa. Petri plates containing glass slides were sterilized and inoculated with $8 \mathrm{~mL}$ of double-strength nutrient broth containing $\sim 2 \times 10^{5} \mathrm{CFU} / \mathrm{mL} P$. aeruginosa overnight culture and incubated at $37^{\circ} \mathrm{C}$ for 24 hours. Glass slides were washed with sterile water, dried, and stained with $1 \%$ crystal violet. Excess crystal violet was washed with deionized water, glass slides were dried, and micrographs were obtained with a light microscope (Leica Model CME Microscope, Buffalo, NY, USA) using immersion oil. Images were captured from different fields [35].

2.9. FT-IR Characterization of Extracellular Polymeric Substance (EPS). Test tubes containing $8 \mathrm{~mL}\left(\sim 2 \times 10^{5} \mathrm{CFU} /\right.$ $\mathrm{mL}$ ) bacteria were incubated at $37^{\circ} \mathrm{C}$ without agitation, to allow biofilm formation. After 48 hours of incubation, the dense slimy matrix formed at the media-air interface was decanted and washed with 30\% acetic acid and ice-cold acetone [36]. The infrared spectrum of the EPS was acquired as described previously.

2.10. Inhibition of Biofilm Formation. In order to estimate the minimum biofilm inhibition concentration, biofilm formation assay was performed [27, 37]. Microtiter plates containing bacteria with or without peptides at various concentrations were incubated for 24 hours at $37^{\circ} \mathrm{C}$ without agitation. Plates were then washed with deionized water to remove unattached bacteria and stained with $0.1 \%$ crystal violet followed by absorbance measurements at $595 \mathrm{~nm}$ (BioTeK ${ }^{\circledR}$ Synergy H1 Multimode Microplate Reader, Germany). Percentage biofilm inhibition was estimated from the normalized OD values using the following equation:

$$
\% \text { inhibition }=\frac{\text { control }- \text { treated }}{\text { control }} \times 100 .
$$

2.11. Inhibition of Biofilm Formation on Glass Slides. Petri plates containing glass slides were sterilized and inoculated with $8 \mathrm{~mL}$ of double-strength nutrient broth containing $\sim 2 \times 10^{5} \mathrm{CFU} / \mathrm{mL} P$. aeruginosa overnight culture with or without peptide treatment and incubated at $37^{\circ} \mathrm{C}$ for 24 hours. Glass slides were washed with sterile water, dried, and stained with $1 \%$ crystal violet. Excess crystal violet was washed with deionized water, glass slides were dried, and micrographs were obtained with a light microscope (Leica Model CME Microscope, Buffalo, NY, USA) using immersion oil. Images were captured from different fields.

2.12. Eradication of Preformed Biofilm on Glass Slides. Petri plates containing glass slides were sterilized and inoculated with $8 \mathrm{~mL}$ of double-strength nutrient broth containing $\sim 2 \times 10^{5} \mathrm{CFU} / \mathrm{mL} P$. aeruginosa overnight culture and incubated at $37^{\circ} \mathrm{C}$ for 24 hours. The plates, which had glass slides with preformed biofilms, were then treated with $2.5 \mathrm{mg} / \mathrm{mL}$ of peptide mix prepared in sterile doublestrength nutrient broth and incubated for a further 24 hours. Glass slides were then washed with sterile water, dried, and stained with $1 \%$ crystal violet. Excess crystal violet was washed with deionized water, glass slides were dried, and micrographs were obtained with a light microscope (Leica Model CME Microscope, Buffalo, NY, USA) using immersion oil. Images were captured from different fields.

2.13. Pyoverdine Quantification. P. aeruginosa inoculum was incubated in the absence (growth control) and presence of sub-MIC (1/2 MIC, 1/4 MIC, 1/8 MIC, 1/16 MIC, and 1/32 MIC) doses of gentamicin and peptide extract at $37^{\circ} \mathrm{C}$ for 48 hours. Culture media were then centrifuged at $4,000 \mathrm{rpm}$ for 45 minutes. One hundred microliters of cell-free supernatant was dispensed into a 96-well microtiter plate for pyoverdine measurement. The relative concentration of pyoverdine in all treated supernatants with respect to control (no drug) was measured by fluorescence (BioTeK ${ }^{\circledR}$ Synergy H1 Multimode Microplate Reader, Germany) at an excitation wavelength of $405 \mathrm{~nm}$ and an emission wavelength of $465 \mathrm{~nm}$ [27, 38]. Percentage inhibition was determined relative to untreated culture (control) by the expression in (1).

2.14. Pyocyanin Quantification. P. aeruginosa was incubated as described in the pyoverdine inhibition assay. Cell-free supernatants were collected after centrifugation at $4000 \mathrm{rpm}$ for 45 minutes. Four milliliters of chloroform was 
then added to $8 \mathrm{~mL}$ of the supernatant and vortexed 10x for 2 seconds (green-blue chloroform sinks to the bottom of the tube). Samples were then centrifuged for 2 minutes at $4000 \mathrm{rpm}$, and the supernatant on top of the green-blue chloroform was decanted. Three milliliters of $0.2 \mathrm{M} \mathrm{HCl}$ was then added to each tube and vortexed 10x for $2 \mathrm{~s}$ and then centrifuged for 2 minutes at $4000 \mathrm{rpm}$. Supernatant (pink layer) was transferred into a cuvette and absorbance measured at $520 \mathrm{~nm}$ [39]. Pyocyanin concentration ( $\mu \mathrm{g} /$ $\mathrm{mL}$ ) was calculated by multiplying the absorbance value at $520 \mathrm{~nm}$ with 17.072 (molar extinction coefficient of pyocyanin at $520 \mathrm{~nm}$ ). Percentage inhibition was determined relative to untreated culture (control) by the expression in (1).

2.15. Protease Expression Assay. P. aeruginosa inoculum was incubated in the absence (growth control) and presence of sub-MIC (1/2 MIC, 1/4 MIC, 1/8 MIC, 1/16 MIC, and 1/32 MIC) doses of standard antibiotic gentamicin and peptide mix at $37^{\circ} \mathrm{C}$ for 48 hours. Culture media were transferred into centrifuge tubes and then centrifuged at $4000 \mathrm{rpm}$ for 45 minutes. The amount of L-tyrosine released from the degradation of casein by proteases in the cell-free supernatant was evaluated using standard protocols as described elsewhere [40]. The amount of L-tyrosine released by proteases expressed in the untreated cultures was used to estimate the percentage inhibition of protease expression by (1).

2.16. Swarming Motility Assay. Swarming motility was investigated in treated and untreated cultures of $P$. aeruginosa using a swarming motility media composed of $0.8 \%$ nutrient broth, $0.5 \%$ nutrient agar, and $0.5 \%$ glucose. The media surface was briefly dried, and bacterial cells from overnight cultures treated with or without peptide mix were gently inoculated using a sterile toothpick at the center of the agar surface and incubated at $37^{\circ} \mathrm{C}$ for 24 hours and 48 hours. The diameter of the circular pattern was measured [41].

2.17. Data Analyses. All data analyses and graphs were done using GraphPad Prism version 6.0 for Windows (GraphPad Software, San Diego, CA, USA) and Microsoft Excel 2013. Data values of experimental results were recorded as the mean \pm standard deviation. Where necessary, significance was determined by one-way ANOVA.

\section{Results}

3.1. Infrared Characterization. The infrared spectrum of the peptide mix isolated from Olivancillaria hiatula is shown in Figure 1. The spectrum was consistent with that of an archetypal peptide. Peaks representative of $-\mathrm{N}-\mathrm{H}, \mathrm{C}=\mathrm{O}$, and $-\mathrm{C}-\mathrm{H}$ stretching and bending vibrations were visible in the spectrum.

3.2. Minimum Inhibitory Concentration. In order to assess the effect of peptide mix on biofilm formation, peptide concentrations that were to be evaluated need to have little or no effect on the viability of the microbes. Thus, sub-MIC doses were to be used in the assays. The minimum inhibitory concentration (MIC) of the peptide mix on $P$. aeruginosa was evaluated and found to be $39.06 \mu \mathrm{g} / \mathrm{mL}$. The MIC of gentamicin was also determined and was found to be $1.95 \mu \mathrm{g} / \mathrm{mL}$.

3.3. Bacterial Growth Rate and Growth Curves. Quorum sensing is population-dependent; thus, to estimate interference, bacterial growth in the presence or absence of peptide mix at MIC and sub-MICs was examined using 96-well plate based $\mathrm{OD}_{600}$ measurements (Figure 2(a)). The log and stationary phases in the growth control (GC) began at 5 and 12 hours, respectively. At the MIC, a lag time of 16 to 18 hours was observed with decreased absorbance at log or stationary phase. At sub-MICs, the lag time was prolonged to $\sim 10$ hours and log phase to $\sim 23$ hours with no observable stationary phase as observed in the growth control. After 24 hours (Figure 2(b)), there was no significant difference in $\mathrm{OD}_{600}$ absorptions, indicating that bacteria cells did grow to about the same extent, in spite of the differences in growth pattern between treated and untreated groups.

3.4. Biofilm Formation and Characterization. The Pseudomonas aeruginosa ATCC 4853 strain used in this study proved to be ideal for this study as biofilm formation was observed on both glass slides and in microtiter plates. The EPS of the biofilm formed was also characterized by infrared spectroscopy and the spectrum obtained (Figure 3) showed peaks largely consistent with that of a biofilm matrix. There were absorption bands arising from $-\mathrm{N}-\mathrm{H}$ and $-\mathrm{O}-\mathrm{H}$ stretches in proteins and sugars $\left(3280-3450 \mathrm{~cm}^{-1}\right),-\mathrm{C}-\mathrm{H}-$ stretches in lipids and fatty acids $\left(2850-2980 \mathrm{~cm}^{-1}\right)$, amide carbonyl $(-\mathrm{C}=\mathrm{O})$ stretches in proteins $\left(1540-1630 \mathrm{~cm}^{-1}\right)$, as well as $\mathrm{O}$-acetyl (-C-O-C-) stretches in polysaccharides and nucleic acids $\left(900-1380 \mathrm{~cm}^{-1}\right)$. The spectrum was consistent with those published elsewhere [36, 44].

3.5. Effect of Peptide Mix on Biofilm Formation. To evaluate the effects of peptides on biofilm formation, OD measurements and microscopy were used. Light microscopy revealed strong biofilm-forming ability in the control group (Figure 4(a)) owing to high absorption of the crystal violet dye. The treated group (Figure 4(b)) showed markedly reduced crystal violet-stained grooves in the micrograph, with fewer crystal violet stains in the 1/2 MIC-treated setup. The peptide mix also disrupted pre-formed biofilm on the glass slides as observed by the disruption of biofilm in the treated group relative to the control (Figure $4(\mathrm{c})$ ). The microtiter plate-based assay was also used to determine the effect of peptide mix on biofilm formation. At the MIC, biofilm formation was inhibited to about $55 \%$. This reduced to $22 \%$ at $1 / 2$ MIC and dropped to a low of $4 \%$ at $1 / 16$ MIC. However, inhibition increased to $18 \%$ at $1 / 32 \mathrm{MIC}$ (Figure 4(d)). 


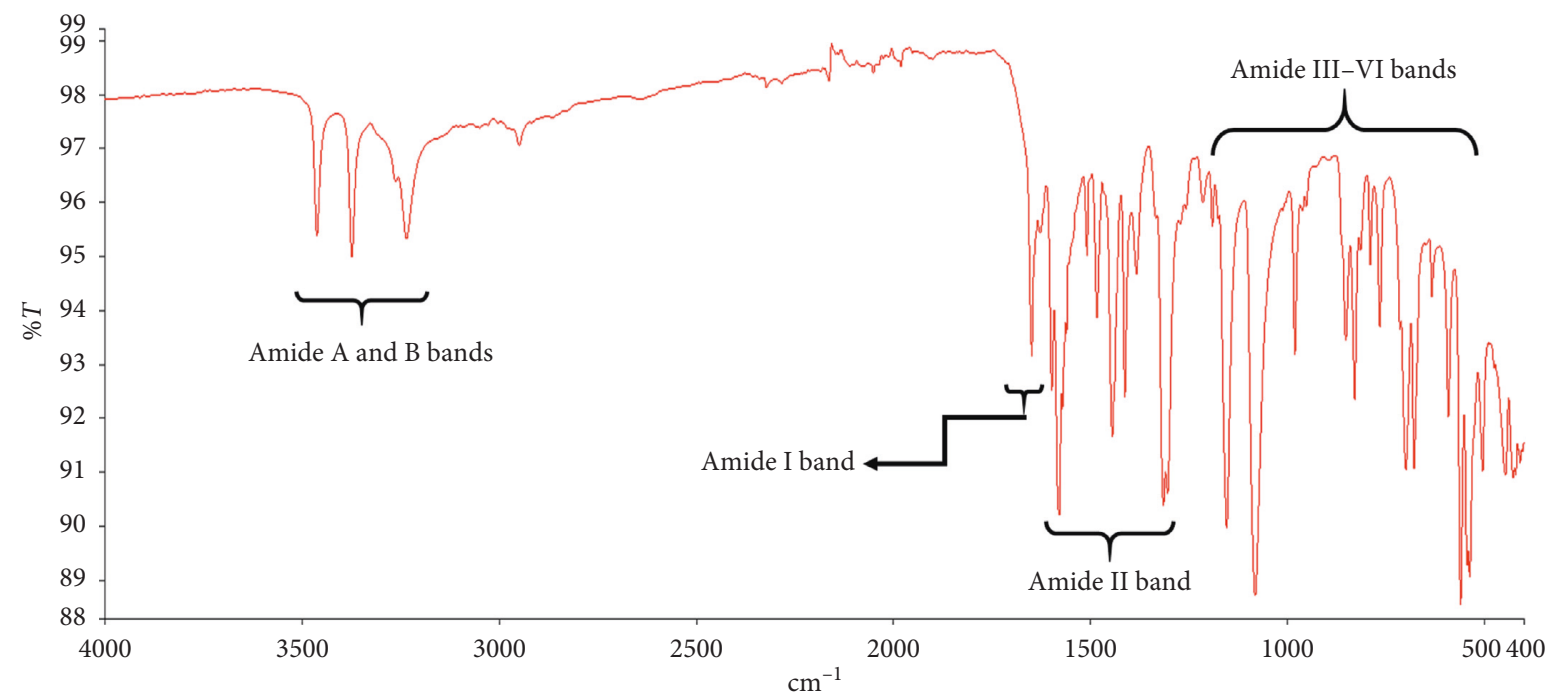

FIGURE 1: Fourier transform infrared (FTIR) spectrum of the peptide mix isolated from Olivancillaria hiatula. Peak characteristics of the amide $\mathrm{A}$ and $\mathrm{B}$ bands $\left(3100-3500 \mathrm{~cm}^{-1}\right)$, amide I band $\left(1600-1700 \mathrm{~cm}^{-1}\right)$, amide II band $\left(1480-1600 \mathrm{~cm}^{-1}\right)$, and amide III-VI bands $\left(500-1300 \mathrm{~cm}^{-1}\right)$ have been shown, as described elsewhere [42, 43].

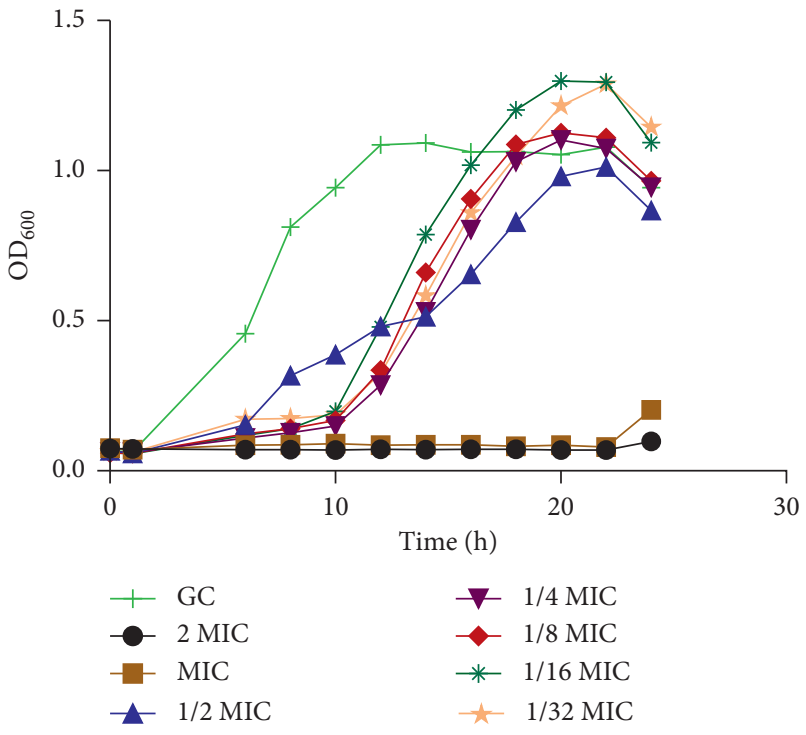

(a)

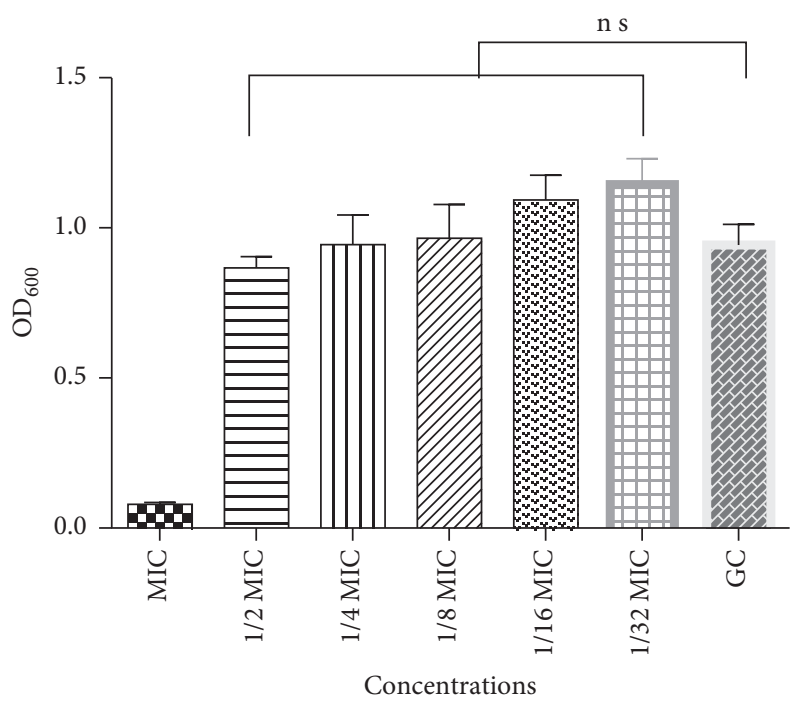

(b)

Figure 2: (a) Growth curve of Pseudomonas aeruginosa ATCC 4853 in the absence (GC) and presence of varying concentrations of peptide mix (MIC, 1/32 MIC). After 24 hours of growth, Pseudomonas aeruginosa absorptions $\left(\mathrm{OD}_{600}\right)$ were similar, with no significant difference between all treated cells relative to the untreated control. (b) Cell density of Pseudomonas aeruginosa ATCC 4853 cultivated in the absence (GC) and presence of sub-MICs of peptide mix. Cell density was recorded after 24 hours of growth. Mean values of 3 independent experiments and their standard deviations are shown. When compared with the untreated control (GC), no significant difference $(P<0.05)$ was observed. Cell density for MIC treatment was significantly different $(P<0.0001)$ from that of sub-MIC-treated groups $($ MIC, minimum inhibitory concentration; GC, growth control).

3.6. Effect of Peptide Mix on Secretion of Virulence Factors. Since QS mediates the expression of genes responsible for the production and secretion of virulence factors in $P$. aeruginosa, we sought to evaluate the ability of the peptide mix to interfere with the production of pyoverdine, pyocyanin, and proteases by $P$. aeruginosa. Gentamicin is a known QS inhibitor and so was used as a positive control [27]. Relative fluorescence of pyoverdine in treated cultures showed that pyoverdine production was reduced in a largely dose-dependent manner. At 1/2 MIC and 1/32 MIC, gentamicin reduced pyoverdine production by $72 \%$ and $66 \%$, respectively, whereas the peptide mix reduced pyoverdine production by $69 \%$ and $43 \%$, respectively (Figure 5). For pyocyanin production, $85 \%$ and $13 \%$ reductions were observed for gentamicin at $1 / 2 \mathrm{MIC}$ and 


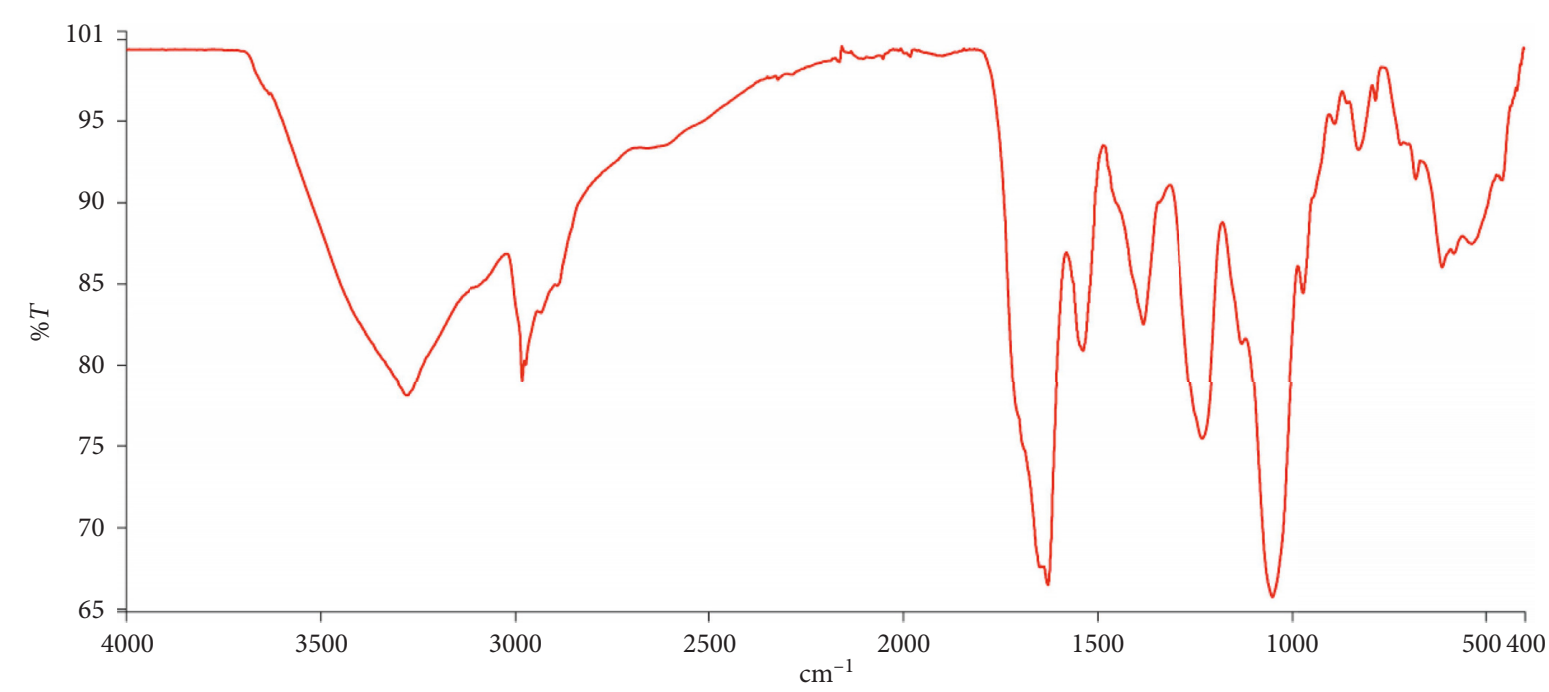

FIgURE 3: FTIR spectrum of the EPS of Pseudomonas aeruginosa ATCC 4853. The EPS matrix was precipitated from air-media interface and contains absorption bands arising from $\mathrm{N}-\mathrm{H}$ and $\mathrm{O}-\mathrm{H}$ stretches in proteins and sugars $\left(3280-3450 \mathrm{~cm}^{-1}\right),-\mathrm{C}-\mathrm{H}-$ stretches in lipids and fatty acids $\left(2850-2980 \mathrm{~cm}^{-1}\right)$, amide carbonyl $(-\mathrm{C}=\mathrm{O})$ stretches in proteins $\left(1540-1630 \mathrm{~cm}^{-1}\right)$, as well as O-acetyl $(-\mathrm{C}-\mathrm{O}-\mathrm{C}-)$ stretches in polysaccharides and nucleic acids $\left(900-1380 \mathrm{~cm}^{-1}\right)[36,44]$.

1/32 MIC, respectively, whereas $61 \%$ and $23 \%$ reductions were observed for peptide mix at similar concentrations. Pyocyanin inhibition in both cases was similar at $1 / 2 \mathrm{MIC}$ and 1/8 MIC (Figure 6). Untreated cell-free supernatants evaluated for the presence of proteases yielded elevated levels of protease activity owing to their ability to digest casein and release large amounts of amino acids. Levels ( $\mu$ moles) of L-tyrosine estimated from a standard curve were used to assess the extent of protease inhibition in untreated and treated cultures. In gentamicin cultures, there was $87.06 \%$ to $74.60 \%$ inhibition of protease expression compared to untreated cultures. When treated with peptide mix, cultures gave moderate inhibition of protease expression-51.21\% and $10.63 \%$, at $1 / 2 \mathrm{MIC}$ and $1 / 32 \mathrm{MIC}$, respectively (Figure 7 ).

3.7. Effect on Swarming Motility. There was a marked reduction in swarming motility of $P$. aeruginosa treated with peptide mix. Reduction in motility was also dose-dependent. After 24 hours, swarm diameters varied between $5 \mathrm{~mm}$ and $22 \mathrm{~mm}$ for peptide-treated culture inoculums. This increased after $48 \mathrm{~h}$ of incubation to between $26 \mathrm{~mm}$ and $44 \mathrm{~mm}$ (Figure 8).

\section{Discussions}

Bacteria that exist in their biofilm state have been found to be more virulent than their planktonic counterparts. These bacteria secrete a hydrated matrix that consists of polysaccharides, proteins, nucleic acids, and lipids. Biofilm-associated bacteria often cause infections that are difficult to treat, primarily due to their multidrug-resistant nature. New and effective molecules to treat such infections are therefore urgently needed. There is increasing evidence about the involvement of QS in biofilm formation, maintenance, and dispersal [45]. QS controls the expression of genes that are responsible for biofilm formation, growth control, production of virulence factors, and motility in $P$. aeruginosa [24]. Quorum sensing inhibitors (QSIs) have therefore been proposed as potential antibiofilm agents [22, 27, 45]. Antimicrobial peptides have shown great promise as potential therapeutics for infectious disease control, and a number of them are currently in advanced clinical trials $[26,30,46]$. The peptide mix from Olivancillaria hiatula has shown interesting antimicrobial potential [47] and was therefore evaluated for its ability to attenuate biofilm formation and interfere with other QS-mediated processes in the model biofilm-forming pathogenic organism $P$. aeruginosa.

The peptide mix from Olivancillaria hiatula was obtained via acetone precipitation of an acetic acid extract. The infrared (IR) spectrum of the extract revealed characteristic amide I absorptions at about $1650 \mathrm{~cm}^{-1}$. This is due to carbonyl $(-\mathrm{C}=\mathrm{O})$ stretching vibrations of the amide functionality. The amide II absorptions observed from 1480 to $1575 \mathrm{~cm}^{-1}$ were prominent and are due to $-\mathrm{N}-\mathrm{H}$ bending and $-\mathrm{C}-\mathrm{N}$ stretching vibrations. The absorptions between 3200 and $3500 \mathrm{~cm}^{-1}$ represent the amide $\mathrm{A}$ and $\mathrm{B}$ bands and are due to $-\mathrm{N}-\mathrm{H}$ stretching vibrations. Finally, there were peaks consistent with amide III-VI regions $\left(500-1300 \mathrm{~cm}^{-1}\right)$ in the spectrum. The infrared spectrum therefore showed a sample rich in peptides $[42,43,48]$.

The $P$. aeruginosa strain used in this study proved to be a very good biofilm-forming microbe. The micrograph obtained after crystal violet staining showed deep, violet grooves indicative of a biofilm. The infrared spectrum of the EPS matrix precipitated from the biofilm is consistent with that studied by other researchers $[36,44]$. The results indicated the presence of a mixture of macromolecules such as proteins, nucleic acids, lipids, and polysaccharides.

Due to the antimicrobial action of peptides isolated from molluscs $[26,32,33]$, we evaluated the MIC of the peptide mix against $P$. aeruginosa. An MIC of $39 \mu \mathrm{g} / \mathrm{mL}$ indicates a good 


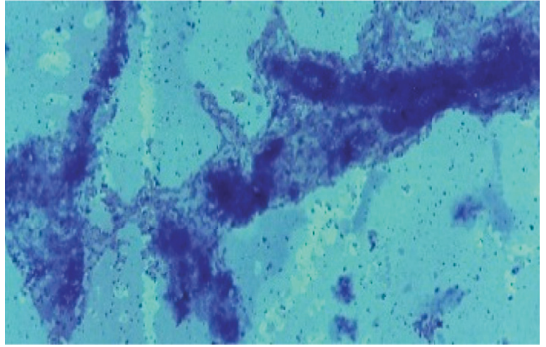

(a)

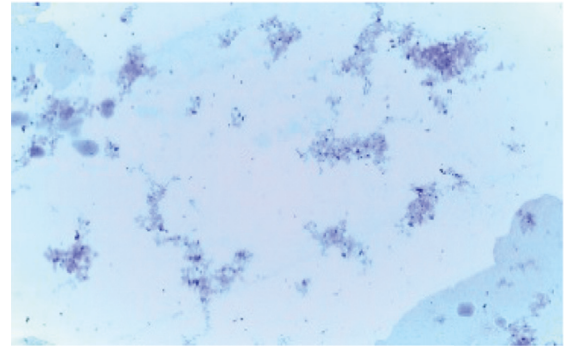

(b)

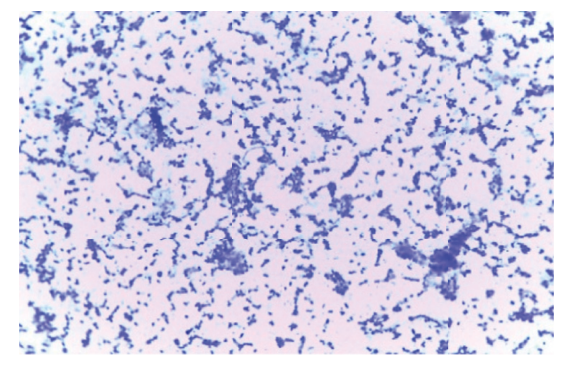

(c)

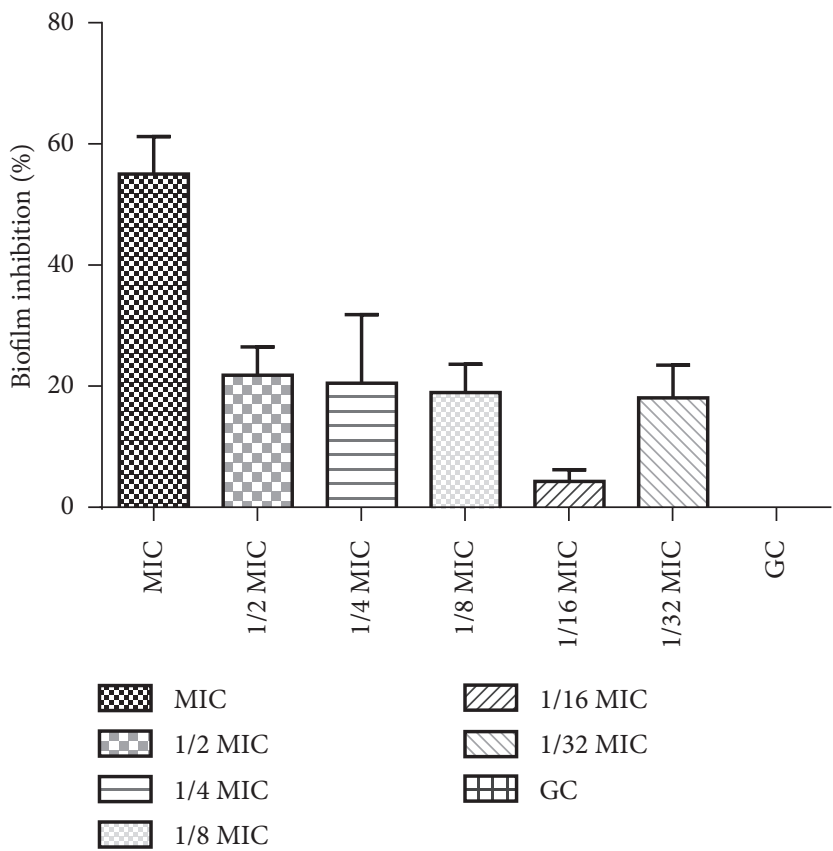

(d)

Figure 4: Antibiofilm activity of peptide mix. Micrographs of $P$. aeruginosa biofilm on glass slides: (a) untreated control showing dense biofilm in the absence of peptide, (b) biofilm inhibition in the presence of $1 / 2 \mathrm{MIC}$ of peptide mix, and (c) disruption of preformed biofilm treated with $2.5 \mathrm{mg} / \mathrm{mL}$ of peptide mix. (d) Antibiofilm effect of peptide concentration on Pseudomonas aeruginosa. Each bar represents mean \pm SD of triplicate experiments in a microtiter plate-based assay.

antibacterial agent. An MIC dose, however, will completely inhibit the growth of the bacteria and thus prevent biofilm formation, motility, or virulent factors' expression. Additionally, since biofilm formation, virulent factors' production, and swarming motility are all dependent on bacteria quorum size, it was important to show that the sub-MIC of peptides to be used did not inhibit bacterial growth. We thus monitored bacterial growth kinetics at $\mathrm{OD}_{600}$. There was no significant difference in the $\mathrm{OD}_{600}$ absorption between untreated group (growth control) and the sub-MIC-treated cells (Figure 2(a)). While there were differences in the rate of growth, the $\mathrm{OD}_{600}$ after 24 hours clearly showed that bacteria growth was uninhibited (Figure 2(b)) and quorum sizes could be attained. This indicates that any effect on any of the processes investigated does not occur as a result of attenuation of bacteria growth, but rather due to interference of peptide mix in important cellular processes.

Sub-MIC doses of the peptide mix were evaluated for their ability to modulate biofilm formation in P. aeruginosa. Biofilm inhibition was in the range of 4-22\%. Analysis of our data showed that peptide concentrations between the MIC and 1/2 MIC will be required to inhibit biofilm formation by about $50 \%$. The micrographs obtained from the glass slide-based assay show the reduction in biofilm formed on the glass slide from the treated culture in comparison with that of the control. The microtiter assay is thus complementary to the glass slide-based assay. However, the microtiter plate-based assay provides a means for quantification. The peptide mix was also able to scatter preformed biofilm. The eradication of pre-formed biofilm required a much higher concentration of peptide mix $(2.5 \mathrm{mg} / \mathrm{mL})$ to observe any effect. This suggests that the peptide mix probably functions by interfering with the biofilm formation process, rather than removing biofilm that has already been formed. It has been suggested that antibiofilm peptides function by preventing microbes from adhering to surfaces, killing early surface colonizers, killing preformed biofilm-associated cells, and inhibiting the quorum sensing machinery of the microbe [49]. We postulated that the peptide mix from Olivancillaria hiatula probably interferes with cell-to-cell communication in $P$. 


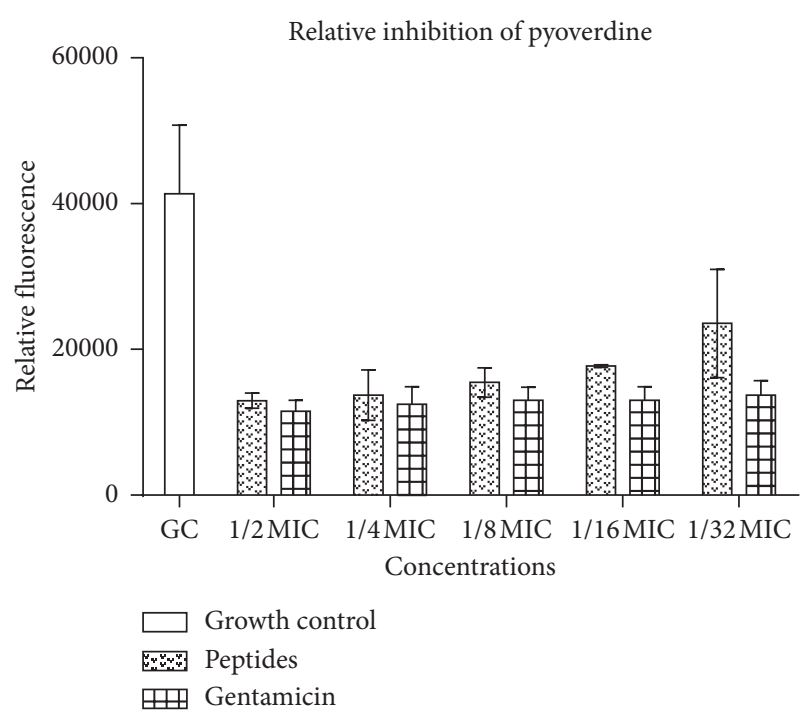

(a)

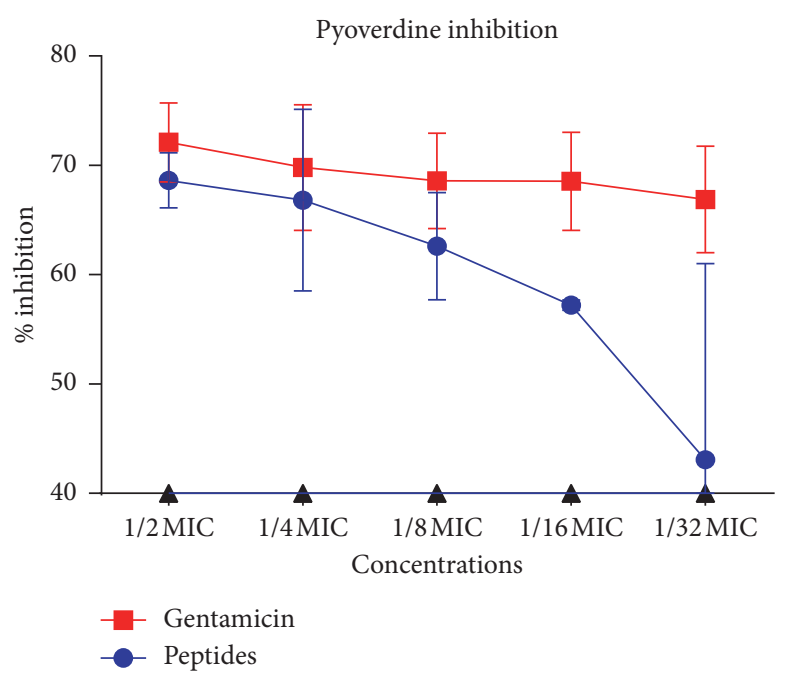

(b)

FIgURE 5: Pyoverdine inhibition. (a) Relative fluorescence of pyoverdine secreted by Pseudomonas aeruginosa with and without sub-MIC doses of the peptide mix and standard drug, gentamicin. Each bar represents mean \pm SD of fluorescence intensities of 3 independent experiments. (b) Percentage inhibition of pyoverdine secretion in Pseudomonas aeruginosa in the presence of sub-MIC doses of the peptide mix and gentamicin. Percentage inhibitions were computed with respect to the fluorescence of the control group. Each bar represents mean $\pm S D$ of triplicate experiments.

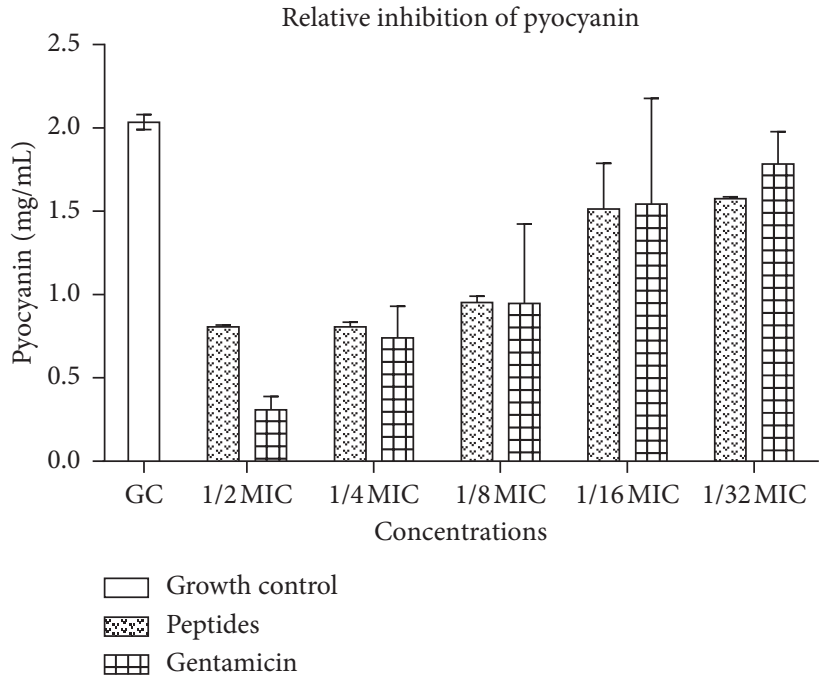

(a)

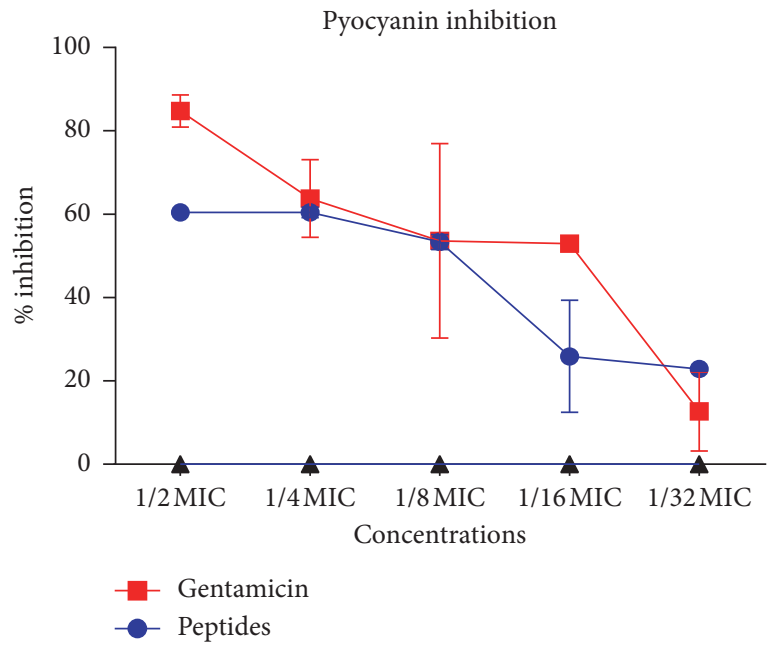

(b)

Figure 6: Pyocyanin inhibition. (a) Pyocyanin production by Pseudomonas aeruginosa with and without sub-MIC doses of the peptide mix and standard drug, gentamicin. Each bar represents mean \pm SD of pyocyanin levels in 3 independent experiments. (b) Percentage inhibition of pyocyanin secretion in Pseudomonas aeruginosa in the presence of sub-MIC doses of the peptide mix and gentamicin. Percentage inhibitions were computed with respect to the control group. Each bar represents mean \pm SD of triplicate experiments.

aeruginosa and thus inhibits biofilm formation via this route.

Since QS in P. aeruginosa also controls motility and the expression of virulence factors such as pyocyanin, pyoverdine, and proteases [24], peptide mix should also interfere with the expression and production of these virulent factors as well as the motility of the microorganism. We therefore evaluated the levels of pyocyanin, pyoverdine, and proteases expressed by $P$. aeruginosa in the presence and absence of sub-MIC doses of the peptide mix. We also examined the effect of these peptide concentrations on $P$. aeruginosa swarming motility. Pyoverdine levels were reduced in the presence of the peptide mix, with inhibitions occurring in an essentially dose-dependent manner. At 1/2 MIC, pyoverdine production was inhibited by over $60 \%$. For pyocyanin, production was inhibited by about $61 \%$ at $1 / 2$ MIC, whereas over 


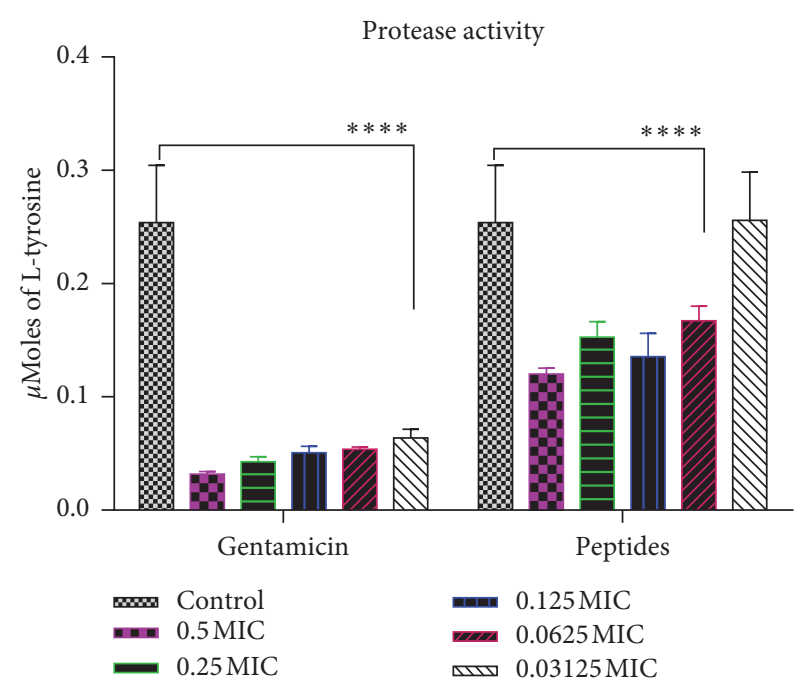

(a)

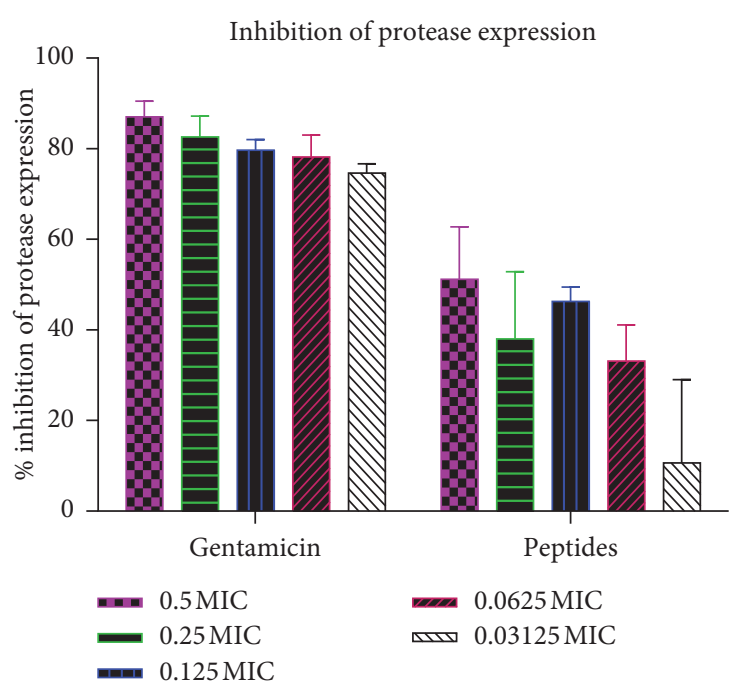

(b)

FIgURE 7: Protease inhibition. (a) Levels of tyrosine produced from casein digestion by proteases in cell-free supernatants of treated and untreated cultures of Pseudomonas aeruginosa. Treated cultures were prepared in the presence of sub-MIC doses of the peptide mix and standard drug, gentamicin. Each bar represents mean \pm SD of tyrosine concentration in 3 independent experiments. (b) Percentage inhibition of protease expression in Pseudomonas aeruginosa in the presence of sub-MIC doses of the peptide mix and gentamicin. Percentage inhibitions were computed with respect to the control group. Each bar represents mean \pm SD of triplicate experiments.

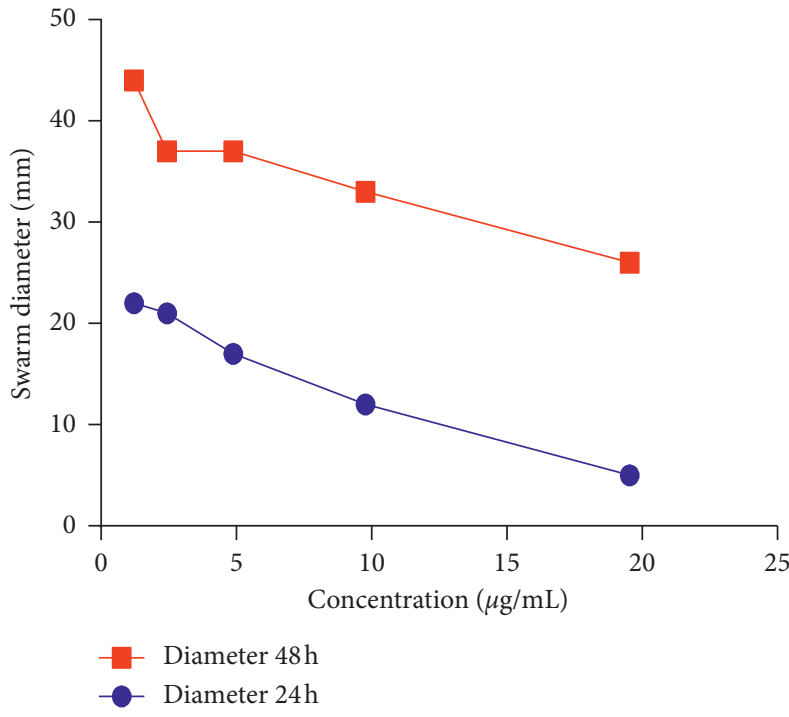

(a)

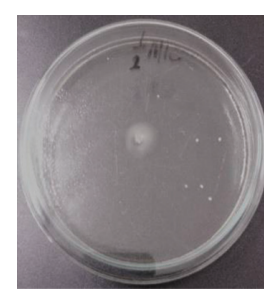

$1 / 2$ MIC

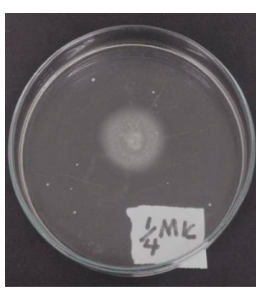

$1 / 4$ MIC

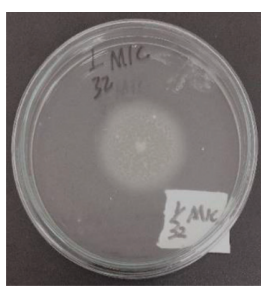

$1 / 32 \mathrm{MIC}$

(b)

FIgURE 8: Inhibition of swarming motility. (a) Line plot of Pseudomonas aeruginosa swarm diameter (mm) on an agar plate. Each well was seeded with bacteria and peptide mix (sub-MIC doses of the peptide mix) and incubated for 24 hours (blue line) or 48 hours (red line). Each point is the mean of triplicate experiments. (b) Representative pictures of swarming motility of Pseudomonas aeruginosa in the presence of $1 / 2$ MIC, $1 / 4$ MIC, and 1/32 MIC doses of the peptide mix.

$50 \%$ reduction in protease expression was also observed. These results show that the peptide mix from Olivancillaria hiatula does indeed interfere with the production of virulent factors, and the same mechanism is used in biofilm inhibition.

The basic $P$. aeruginosa siderophore, pyoverdine, is able to both sequester iron from host depots and act as a QS signaling molecule. Iron-bound pyoverdine interacts with the $P$. aeruginosa cell receptor FpvA, and this complex in turn interacts with the antisigma factor, FpvR, causing the upregulation of exotoxin A, an endoprotease, and of pyoverdine itself [50]. Pyocyanin induces oxidative stress in host and promotes the secretion of airway mucus. It has also been reported that $P$. aeruginosa secretes proteases as a virulent factor to progress pathogenesis [50]. All these virulent factors 
are also important for biofilm development and maintenance and contribute significantly to the devastating nature of $P$. aeruginosa infections.

We also investigated the effect of peptides on swarming motility. Cells treated with peptide mix showed less swarming motility when compared to the untreated control. Similar to the effects shown by peptide mix on virulent factors, a dose-dependent relationship was observed. Swarming is an intricate communal behavior developed by microbes due to several environmental signals, and this facilitates microbial motility on a semisolid surface and is used in the colonization of host tissues. Swarming motility in $P$. aeruginosa is flagella-driven, and this phenomenon is controlled by QS. Swarming motility also positively influences surface attachment-the $1^{\text {st }}$ step in microbial biofilm formation [27, 41].

The ability of the peptide mix from Olivancillaria hiatula to inhibit biofilm formation in $P$. aeruginosa as well as swarming motility and the expression of virulent factors therefore suggests that the mode of action involves the inhibition of a common factor in all these processes. Since QS controls all these activities in P. aeruginosa, the peptide mix probably interferes with cell-to-cell communication. Very few drugs on the market inhibit both quorum sensing and biofilm formation [27]. Identification of compounds and extracts that perform both dual functions limits the likelihood for the formation of antimicrobial resistance and provides a facile strategy for control of pathogenic microbes. The promise shown by the peptide mix from $O$. hiatula in this regard provides an opportunity for developing novel therapeutics to target pathogenic bacteria.

\section{Conclusion}

In summary, the results from the present study shows that the peptide mix from Olivancillaria hiatula is a potent antibiofilm agent that functions probably by attenuating QS in $P$. aeruginosa. Identification of the peptide sequence will facilitate unambiguous establishment of the mode of action. Efforts in this regard are currently underway.

\section{Data Availability}

All data generated or analyzed during this study are included in this manuscript.

\section{Disclosure}

The authors received no direct funding for this research.

\section{Conflicts of Interest}

The authors declare that they have no conflicts of interest.

\section{Authors' Contributions}

LSB conceived the study. LSB, ENG, and HSA designed the experiments, analyzed the data, and prepared the manuscript. ENG collected the samples. HSA and ENG carried out all the experiments. All authors read and approved the final manuscript.

\section{Acknowledgments}

The authors are grateful to the Departments of Chemistry and Pharmaceutical Microbiology and the Central Laboratory, all of KNUST for the use of their laboratory space and facilities for this study. The authors also express their gratitude to Dr. Isaac Kingsley Amponsah (Department of Pharmacognosy, KNUST) for being an inspiration and helpful discussions. The authors acknowledge Mr. Francis Amankwaah of the Department of Pharmaceutical Microbiology, KNUST, and Miss Lorinda Adu-Gyamfi of the University of Energy and Natural Resources, Sunyani, Ghana, for technical support.

\section{References}

[1] P. Beyer, V. Moorthy, S. Paulin et al., "The drugs don't work: WHO's role in advancing new antibiotics," The Lancet, vol. 392, no. 10144, pp. 264-266, 2018.

[2] D. Jasovský, J. Littmann, A. Zorzet, and O. Cars, "Antimicrobial resistance-a threat to the world's sustainable development," Upsala Journal of Medical Sciences, vol. 121, no. 3, pp. 159-164, 2016.

[3] K. Clifford, D. Desai, C. Prazeres da Costa et al., "Antimicrobial resistance in livestock and poor quality veterinary medicines," Bulletin of the World Health Organization, vol. 96, no. 9, pp. 662-664, 2018.

[4] K. Mylona, P. Maragkoudakis, L. Miko et al., "Viewpoint: future of food safety and nutrition-seeking win-wins, coping with trade-offs," Food Policy, vol. 74, pp. 143-146, 2018.

[5] V. M. Vashishtha, "Growing antibiotics resistance and the need for new antibiotics," Indian Pediatrics, vol. 47, no. 6 , pp. 505-506, 2010.

[6] I. N. Okeke, A. Lamikanra, and R. Edelman, "Socioeconomic and behavioral factors leading to acquired bacterial resistance to antibiotics in developing countries," Emerging Infectious Diseases, vol. 5, no. 1, pp. 18-27, 1999.

[7] A. Borer, L. Saidel-Odes, K. Riesenberg et al., "Attributable mortality rate for carbapenem-resistant Klebsiella pneumoniae bacteremia," Infection Control \& Hospital Epidemiology, vol. 30, no. 10, pp. 972-976, 2009.

[8] L. B. Gasink, P. H. Edelstein, E. Lautenbach, M. Synnestvedt, and N. O. Fishman, "Risk factors and clinical impact of Klebsiella pneumoniae carbapenemase-producing K. pneumoniae," Infection Control \& Hospital Epidemiology, vol. 30, no. 12, pp. 1180-1185, 2009.

[9] Z. A. Qureshi, D. L. Paterson, B. A. Potoski et al., "Treatment outcome of bacteremia due to KPC-producing Klebsiella pneumoniae: superiority of combination antimicrobial regimens," Antimicrobial Agents and Chemotherapy, vol. 56, no. 4, pp. 2108-2113, 2012.

[10] S. M. Ribeiro, C. de la Fuente-Núñez, B. Baquir, C. FariaJunior, O. L. Franco, and R. E. W. Hancock, "Antibiofilm peptides increase the susceptibility of carbapenemase-producing Klebsiella pneumoniae clinical isolates to $\beta$-lactam antibiotics," Antimicrobial Agents and Chemotherapy, vol. 59, no. 7, pp. 3906-3912, 2015.

[11] J. M. A. Blair, M. A. Webber, A. J. Baylay, D. O. Ogbolu, and L. J. V. Piddock, "Molecular mechanisms of antibiotic resistance," Nature Reviews Microbiology, vol. 13, no. 1, pp. 42-51, 2015. 
[12] A. Harms, E. Maisonneuve, and K. Gerdes, "Mechanisms of bacterial persistence during stress and antibiotic exposure," Science, vol. 354, no. 6318, Article ID aaf4268, 2016.

[13] J. M. Munita and C. A. Arias, "Mechanisms of antibiotic resistance," Microbiology Spectrum, vol. 4, no. 2, 2016.

[14] T.-F. Mah, B. Pitts, B. Pellock, G. C. Walker, P. S. Stewart, and G. A. O'Toole, "A genetic basis for Pseudomonas aeruginosa biofilm antibiotic resistance," Nature, vol. 426, no. 6964, pp. 306-310, 2003.

[15] J. W. Costerton, P. S. Stewart, and E. P. Greenberg, "Bacterial biofilms: a common cause of persistent infections," Science, vol. 284, no. 5418, pp. 1318-1322, 1999.

[16] J. W. Costerton, Z. Lewandowski, D. E. Caldwell, D. R. Korber, and H. M. Lappin-Scott, "Microbial biofilms," Annual Review of Microbiology, vol. 49, no. 1, pp. 711-745, 1995.

[17] S. L. Gellatly and R. E. W. Hancock, "Pseudomonas aeruginosa: new insights into pathogenesis and host defenses," Pathogens and Disease, vol. 67, no. 3, pp. 159-173, 2013.

[18] E. Matselis and I. G. Roussis, "Proteinase and lipase production by Pseudomonas fluorescens: proteolysis and lipolysis in thermized Ewe's milk," Food Control, vol. 9, no. 5, pp. 251-259, 1998.

[19] D. B. M. Virupakshaiah and V. B. Hemalata, "Molecular identification of Pseudomonas aeruginosa from food borne isolates," International Journal of Current Microbiology and Applied Sciences, vol. 5, no. 6, pp. 1026-1032, 2016.

[20] Y. Sakuragi and R. Kolter, "Quorum-sensing regulation of the biofilm matrix genes (pel) of Pseudomonas aeruginosa," Journal of Bacteriology, vol. 189, no. 14, pp. 5383-5386, 2007.

[21] T. R. De Kievit, R. Gillis, S. Marx, C. Brown, and B. H. Iglewski, "Quorum-sensing genes in Pseudomonas aeruginosa biofilms: their role and expression patterns," Applied and Environmental Microbiology, vol. 67, no. 4, pp. 1865-1873, 2001.

[22] D. G. Davies, M. Parsek, J. Pearson, B. H. Iglewski, J. W. Costerton, and E. P. Greenberg, "The involvement of cell-to-cell signals in the development of a bacterial biofilm," Science, vol. 280, no. 5361, pp. 295-298, 1998.

[23] M. Hentzer, S. A. Rice, M. Givskov et al., "Inhibition of quorum sensing in Pseudomonas aeruginosa biofilm bacteria by a halogenated furanone compound," Microbiology, vol. 148, no. 1, pp. 87-102, 2002.

[24] H. Lade, D. Paul, and J. H. Kweon, "Quorum quenching mediated approaches for control of membrane biofouling," International Journal of Biological Sciences, vol. 10, no. 5, pp. 550-565, 2014.

[25] L. C. M. Antunes, R. B. R. Ferreira, M. M. C. Buckner, and B. B. Finlay, "Quorum sensing in bacterial virulence," $M i$ crobiology, vol. 156, no. 8, pp. 2271-2282, 2010.

[26] M. D. Luca, G. Maccari, and R. Nifosì, "Treatment of microbial biofilms in the post-antibiotic era: prophylactic and therapeutic use of antimicrobial peptides and their design by bioinformatics tools," Pathogens and Disease, vol. 70, no. 3, pp. 257-270, 2014.

[27] M. C. Das, P. Sandhu, P. Gupta et al., "Attenuation of Pseudomonas aeruginosa biofilm formation by Vitexin: a combinatorial study with azithromycin and gentamicin," Scientific Reports, vol. 6, no. 1, p. 23347, 2016.

[28] M. V. Emma, R. U. Kadam, G. Rispoli et al., "Inhibition of Pseudomonas aeruginosa biofilms with a glycopeptide dendrimer containing D-amino acids," MedChemComm, vol. 2, no. 5, pp. 418-420, 2011.

[29] C. de la Fuente-Núñez, F. Reffuveille, E. F. Haney, S. K. Straus, and R. E. W. Hancock, "Broad-spectrum anti-biofilm peptide that targets a cellular stress response," PLoS Pathogens, vol. 10, no. 5, Article ID e1004152, 2014.

[30] B. M. Peters, M. E. Shirtliff, and M. A. Jabra-Rizk, "Antimicrobial peptides: primeval molecules or future drugs?," PLoS Pathogens, vol. 6, no. 10, Article ID e1001067, 2010.

[31] R. E. W. Hancock and G. Diamond, "The role of cationic antimicrobial peptides in innate host defences," Trends in Microbiology, vol. 8, no. 9, pp. 402-410, 2000.

[32] N. Sathyan, E. R. Chaithanya, P. R. Anil Kumar, K. S. Sruthy, and R. Philip, "Comparison of the antimicrobial potential of the crude peptides from various groups of marine molluscs," International Journal of Marine Science, vol. 3, no. 2, pp. 16-22, 2014.

[33] L. S. Borquaye, G. Darko, E. Ocansey, and E. Ankomah, "Antimicrobial and antioxidant properties of the crude peptide extracts of Galatea paradoxa and Patella rustica," SpringerPlus, vol. 4, no. 1, p. 500, 2015.

[34] I. Wiegand, K. Hilpert, and R. E. W. Hancock, "Agar and broth dilution methods to determine the minimal inhibitory concentration (MIC) of antimicrobial substances," Nature Protocols, vol. 3, no. 2, pp. 163-175, 2008.

[35] G. A. O'Toole, "Microtiter dish biofilm formation assay," Journal of Visualized Experiments, no. 47, 2011.

[36] Y. Jiao, G. D. Cody, A. K. Harding et al., "Characterization of extracellular polymeric substances from acidophilic microbial biofilms," Applied and Environmental Microbiology, vol. 76, no. 9, pp. 2916-2922, 2010.

[37] J. Azeredo, N. F. Azevedo, R. Briandet et al., "Critical review on biofilm methods," Critical Reviews in Microbiology, vol. 43, no. 3, pp. 313-351, 2017.

[38] A. Adonizio, K.-F. Kong, and K. Mathee, "Inhibition of quorum sensing-controlled virulence factor production in Pseudomonas aeruginosa by south Florida plant extracts," Antimicrobial Agents and Chemotherapy, vol. 52, no. 1, pp. 198-203, 2008.

[39] K. S. Musthafa, B. S. Sivamaruthi, S. K. Pandian, and A. V. Ravi, "Quorum sensing inhibition in Pseudomonas aeruginosa PAO1 by antagonistic compound phenylacetic acid," Current Microbiology, vol. 65, no. 5, pp. 475-480, 2012.

[40] C. Cupp-Enyard, "Sigma's non-specific protease activity assay-casein as a substrate," Journal of Visualized Experiments, no. 19, 2008.

[41] T. Inoue, R. Shingaki, and K. Fukui, "Inhibition of swarming motility of Pseudomonas aeruginosa by branched-chain fatty acids," FEMS Microbiology Letters, vol. 281, no. 1, pp. 81-86, 2008.

[42] W. Gallagher, "FTIR analysis of protein structure," Course Manual Chemistry, vol. 455, 2009.

[43] J. Kong and S. Yu, "Fourier transform infrared spectroscopic analysis of protein secondary structures," Acta Biochimica et Biophysica Sinica, vol. 39, no. 8, pp. 549-559, 2007.

[44] I. Beech, L. Hanjagsit, M. Kalaji, A. L. Neal, and V. Zinkevich, "Chemical and structural characterization of exopolymers produced by Pseudomonas sp. NCIMB 2021 in continuous culture," Microbiology, vol. 145, no. 6, pp. 1491-1497, 1999.

[45] B. LaSarre and M. J. Federle, "Exploiting quorum sensing to confuse bacterial pathogens," Microbiology and Molecular Biology Reviews, vol. 77, no. 1, pp. 73-111, 2013.

[46] A. J. Otero-González, B. S. Magalhães, M. Garcia-Villarino et al., "Antimicrobial peptides from marine invertebrates as a new frontier for microbial infection control," The FASEB Journal, vol. 24, no. 5, pp. 1320-1334, 2010.

[47] E. N. Gasu, H. S. Ahor, and L. S. Borquaye, "Peptide extract from Olivancillaria hiatula exhibits broad-spectrum 
antibacterial activity," BioMed Research International, vol. 2018, Article ID 6010572, 11 pages, 2018.

[48] W. K. Surewicz, H. H. Mantsch, and D. Chapman, "Determination of protein secondary structure by Fourier transform infrared spectroscopy: a critical assessment," Biochemistry, vol. 32, no. 2, pp. 389-394, 1993.

[49] M. Di Luca, G. Maccari, G. Maisetta, and G. Batoni, "BaAMPs: the database of biofilm-active antimicrobial peptides," Biofouling, vol. 31, no. 2, pp. 193-199, 2015.

[50] P. Nadal Jimenez, G. Koch, J. A. Thompson, K. B. Xavier, R. H. Cool, and W. J. Quax, "The multiple signaling systems regulating virulence in Pseudomonas aeruginosa," Microbiology and Molecular Biology Reviews, vol. 76, no. 1, pp. 46-65, 2012. 

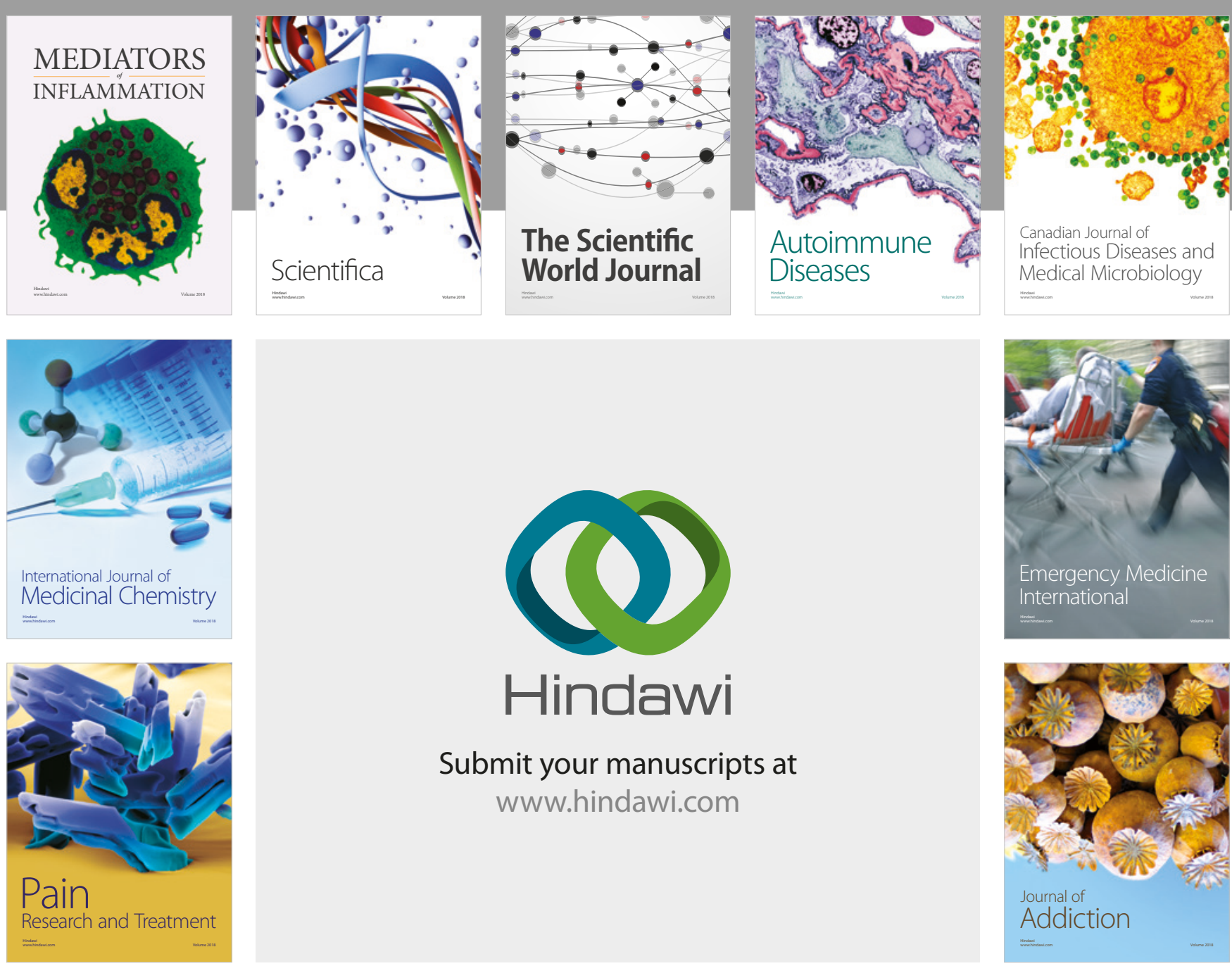

Canadian Journal of
Infectious Diseases and Medical Microbiology

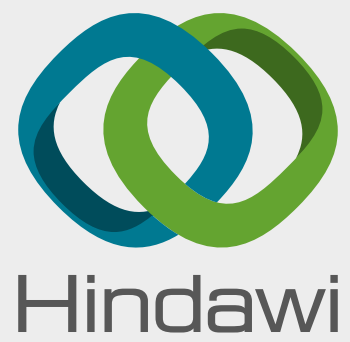

Submit your manuscripts at

www.hindawi.com
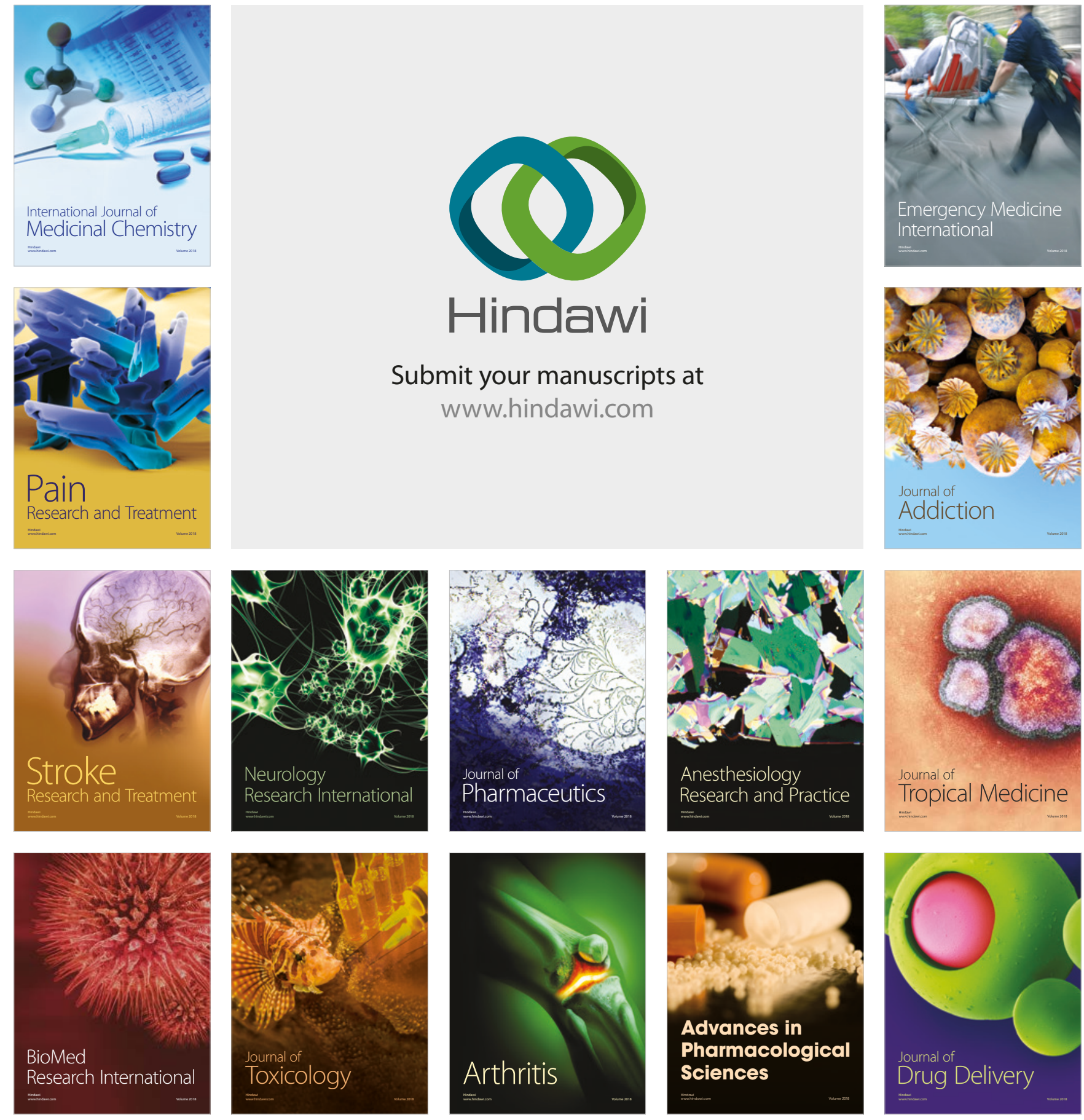